\title{
Cell-free DNA detected by "liquid biopsy" as a potential prognostic biomarker in early breast cancer
}

\author{
Roberta Maltoni ${ }^{1}$, Valentina Casadio ${ }^{2, *}$, Sara Ravaioli2,*, Flavia Foca ${ }^{3}$, Maria \\ Maddalena Tumedei ${ }^{2}$, Samanta Salvi², Filippo Martignano ${ }^{2}$, Daniele Calistri², \\ Andrea Rocca ${ }^{1}$, Alessio Schirone ${ }^{1}$, Dino Amadori ${ }^{1}$, Sara Bravaccini ${ }^{2}$ \\ ${ }^{1}$ Department of Medical Oncology, Istituto Scientifico Romagnolo per lo Studio e la Cura dei Tumori (IRST) IRCCS, Meldola, \\ Italy \\ ${ }^{2}$ Biosciences Laboratory, Istituto Scientifico Romagnolo per lo Studio e la Cura dei Tumori (IRST) IRCCS, Meldola, Italy \\ ${ }^{3}$ Unit of Biostatistics and Clinical Trials, Istituto Scientifico Romagnolo per lo Studio e la Cura dei Tumori (IRST) IRCCS, \\ Meldola, Italy \\ *These authors contributed equally to this work
}

Correspondence to: Sara Bravaccini, email: sara.bravaccini@irst.emr.it

Keywords: CF-DNA, HER2, PI3KCA, prognosis, breast cancer subtypes

Received: August 20, $2016 \quad$ Accepted: January 23, $2017 \quad$ Published: February 06, 2017

\section{ABSTRACT}

As conventional biomarkers for defining breast cancer (BC) subtypes are not always capable of predicting prognosis, search for new biomarkers which can be easily detected by liquid biopsy is ongoing. It has long been known that cell-free DNA (CF-DNA) could be a promising diagnostic and prognostic marker in different tumor types, although its prognostic value in $B C$ is yet to be confirmed. This retrospective study evaluated the prognostic role of CF-DNA quantity and integrity of HER2, MYC, BCAS1 and $P I 3 K C A$, which are frequently altered in BC. We collected 79 serum samples before surgery from women at first diagnosis of BC at Forlì Hospital (Italy) from 2002 to 2010. Twenty-one relapsed and 58 non-relapsed patients were matched by subtype and age. Blood samples were also collected from 10 healthy donors. All samples were analyzed by Real Time PCR for CF-DNA quantity and integrity of all oncogenes. Except for MYC, BC patients showed significantly higher median values of CF-DNA quantity (ng) than healthy controls, who had higher integrity and lower apoptotic index. A difference nearing statistical significance was observed for HER2 short CF-DNA ( $p=0.078$, AUC value: 0.6305). HER2 short CF-DNA showed an odds ratio of 1.39 for disease recurrence with $p=0.056(95 \%$ CI $0.991-1.973)$. Our study suggests that CF-DNA detected as liquid biopsy could have great potential in clinical practice once demonstration of its clinical validity and utility has been provided by prospective studies with robust assays.

\section{INTRODUCTION}

Breast cancer $(\mathrm{BC})$ is the principal cause of cancer death in women worldwide.

As BC is a systemic disease at diagnosis, chemotherapy and hormonal therapy are usually given to eradicate any potential presence of occult micrometastasis after radical surgery, reducing the risk of relapse and improving overall survival according to validated prognostic factors [1].

Despite the locoregional and systemic treatment, $30 \%$ and $50 \%$ of the patients with negative and positive axillary lymph nodes, respectively, relapse after five years of surgery [1].

To date there are no recommended serum markers in clinical practice for monitoring patients and predicting their risk of relapse [2].

Further research is therefore needed to detect through liquid biopsy the biomarkers that can early identify patients at high risk of relapse and set appropriate systemic treatment, especially when clinical and instrumental evidence is not available.

Studies have long suggested that cell-free DNA (CF-DNA) could be used as a potential prognostic 
biomarker also for metastatic spread in solid tumors [3-6]. However, the lack of a standardized method for its evaluation remains one of its main critical issues.

Some authors have demonstrated that the concentration of circulating CF-DNA is higher in cancer patients than in healthy individuals [7-8].

DNA is released into the bloodstream by the apoptotic and necrotic cells of the primary tumor from an early phase of the disease, allowing for the extraction of DNA and the determination of the genetic and epigenetic characteristics [9]. It is well known that apoptotic cells release DNA fragments of 180-200 base pairs whereas necrotic cells release higher molecular weight DNA fragments [9]. It has been shown that DNA from normal apoptotic cells is highly fragmented, whereas DNA from necrotic cancer cells maintains its integrity. We evaluated the Apoptotic Index (AI) and the Integrity Index (II) as biomarkers to identify the patients likely to recur. The latter was calculated as the ratio of the quantity of long fragment/ short fragment; the former was inversely calculated.

This retrospective study aimed to characterize CFDNA as liquid biopsy for identifying patients at risk of relapse as a potential prognostic biomarker for all BC subtypes. We evaluated the role of some of the most frequently altered genes in $\mathrm{BC}$ (HER2, MYC, BCAS1 and $P I 3 K C A)$ in relation to patient prognosis due to a possible correlation with CF-DNA quantity and integrity.

\section{RESULTS}

Patients were matched by subtype and age. Median follow-up was 90 months (range 26-157). The recurrence free survival (RFS) curve showed that $77 \% \quad(95 \%$ CI: $66 \%-85 \%)$ of patients was disease free at 5 years of surgery (Figure 1).

Clinical and histopathologic characteristics of patients in relation to prognosis are reported in Table 1.

No statistically significant difference was found in the extracted quantity of CF-DNA between the two categories of patients (non-relapsed and relapsed; median values, respectively: $9.465 \mathrm{ng}$ - interquartile (iqr) range $5.530-12.700$ vs $9.410 \mathrm{ng}$-iqr range 6.260-10.810, $p=0.673$ ) and between healthy controls and patients (median values, respectively: $12.953 \mathrm{ng}$-iqr range 8.530-17.795 vs $9.440 \mathrm{ng}$-iqr range $5.530-12.190, p=0.078$ ).

In addition to CF-DNA quantity analysis, the II and the AI were reported for each gene, calculated as the ratio of quantity of long fragment /short fragment (II) and short fragment /long fragment (AI).

CF-DNA quantity, II and AI were not statistically different between ER, PgR negative and positive tumors (data not shown). Also G1 and G2 tumors showed no statistically significant lower level of CF-DNA than undifferentiated BCs (data not shown).

Median values of the quantity (ng) of HER2 short, $B C A S 1$ and PI3KCA short CF-DNA were significantly higher in BC patients than in healthy controls (Table 2). Healthy controls showed higher II and lower AI of BCAS1, $M Y C$ and $P I 3 K C A$ oncogenes than BC patients (Table 3 ).

Except for $B C A S 1$ and $P I 3 K C A$ short fragments, the analysis of CF-DNA quantity of each gene (long and short fragment) showed higher median values in relapsed patients than in non-relapsed patients although not statistically significant (Table 4). The indexes of each gene were the same in both relapsed and non-relapsed patients (Table 5).

The relation between quantity of HER2 CF-DNA and HER2 positive BCs (HER2 FISH amplified and/ or IHC positive with $3+$ score) showed no significant difference (data not shown), neither HER2 index differed between the two HER2 types of BC (data not shown).

The ROC curve analysis of the 4 oncogenes was performed to assess the ability of each gene to predict relapse. HER 2 short and II PI3KCA showed AUC values of $0.631(95 \%$ CI $0.476-0.785)$ and 0.615 (95\% CI $0.475-0.755)$, respectively, showing the highest accuracy in predicting relapse. The AUC value of the two-marker combination in a logistic regression model was 0.627 (95\% CI 0.472-0.783), not statistically different from the AUC value of HER2 short alone ( $p=0.609)$. In addition, univariate conditional logistic model of HER2 short CF-DNA showed an odds ratio (OR) of 1.39 for disease recurrence, with $p=0.056$ (95\% CI 0.991-1.973).

\section{DISCUSSION}

There is urgent need for markers detected as liquid biopsy able to identify patients at high risk of relapse or progression. Many studies have failed to demonstrate the use of circulating biomarkers in BC follow-up often due to non-reproducible methods and to the intrinsic biologic value of the marker considered [10].

The assessment of CF-DNA as liquid biopsy could have great potential in clinical practice. Prospective studies on NSCLC patients and tests for target therapies have demonstrated the clinical validity and utility of CFDNA especially in this population [11]. Contrasting results have been reported on what to analyze in CF-DNA and how: different features have been studied in CF-DNA as biomarker, such as integrity, gene copy number variations, mutations [11-15].

Different subsets of patients, timing of sampling, and methodology make analysis of CF-DNA more difficult to standardize and validate. Moreover, high detection rates are not reproducible in early stages of cancer probably due to insufficient DNA quantity of low tumor burden $[14,15]$. High false-positive results in benign lesions in some cohorts have produced discordant results on the specificity of CF-DNA detection at baseline [16, 17]. Not even all patients with progressive metastatic disease appear to release tumor-derived DNA into the bloodstream in quantities measurable with the current technologies, 
Table 1: Patient clinic and histopathologic characteristics in relation to prognosis

\begin{tabular}{|c|c|c|c|c|}
\hline \multirow{2}{*}{ Variable } & $\begin{array}{l}\text { Overall } \\
(n=79)\end{array}$ & $\begin{array}{l}\text { Non-relapsed } \\
\quad(n=58)\end{array}$ & $\begin{array}{c}\text { Relapsed } \\
(n=21)\end{array}$ & \multirow{2}{*}{$p$-value ${ }^{\#}$} \\
\hline & Median (range) & Median (range) & Median (range) & \\
\hline \multirow[t]{2}{*}{ Age } & $57(33-89)$ & $57(33-89)$ & $59(42-79)$ & 0.698 \\
\hline & No. $(\%)$ & No. $(\%)$ & No. $(\%)$ & \\
\hline \multicolumn{5}{|c|}{ Histological subtype } \\
\hline $\mathrm{A}$ & $23(29.1)$ & $17(29.3)$ & $6(28.6)$ & \multirow{4}{*}{0.984} \\
\hline $\mathrm{B}$ & $21(26.6)$ & $16(27.6)$ & $5(23.8)$ & \\
\hline $\mathrm{C}$ & $20(25.3)$ & $14(24.1)$ & $6(28.5)$ & \\
\hline $\mathrm{D}$ & $15(19.0)$ & $11(19.0)$ & $4(19.1)$ & \\
\hline \multicolumn{5}{|l|}{ ER } \\
\hline 0 & $31(39.2)$ & $23(39.7)$ & $8(38.1)$ & \multirow{2}{*}{0.900} \\
\hline$>0$ & $48(60.8)$ & $35(60.3)$ & $13(61.9)$ & \\
\hline \multicolumn{5}{|l|}{ PGR } \\
\hline 0 & $40(50.6)$ & $29(50.0)$ & $11(52.4)$ & \multirow{2}{*}{0.852} \\
\hline$>0$ & $39(49.4)$ & $29(50.0)$ & $10(47.6)$ & \\
\hline \multicolumn{5}{|l|}{ KI67 } \\
\hline $0-19$ & $39(49.4)$ & $29(50.0)$ & $10(47.6)$ & \multirow{2}{*}{0.852} \\
\hline$\geq 20$ & $40(50.6)$ & $29(50.0)$ & $11(52.4)$ & \\
\hline \multicolumn{5}{|l|}{ HER2 Status } \\
\hline NEG & $50(64.9)$ & $37(64.9)$ & $13(65.0)$ & \multirow{2}{*}{0.994} \\
\hline POS & $27(35.1)$ & $20(35.1)$ & $7(35.0)$ & \\
\hline \multicolumn{5}{|l|}{ Grading } \\
\hline G1 & $4(5.5)$ & $3(5.4)$ & $1(5.9)$ & \multirow{3}{*}{1.000} \\
\hline $\mathrm{G} 2$ & $27(36.9)$ & $21(37.5)$ & $6(35.3)$ & \\
\hline G3 & $42(57.6)$ & $32(57.1)$ & $10(58.8)$ & \\
\hline \multicolumn{5}{|l|}{ Therapy } \\
\hline $\mathrm{CT}$ & $27(39.1)$ & $19(38.0)$ & $8(42.1)$ & \multirow{4}{*}{0.353} \\
\hline HT & $21(30.4)$ & $18(36.0)$ & $3(15.8)$ & \\
\hline $\mathrm{CT}+\mathrm{BT}$ & $14(20.3)$ & $9(18.0)$ & $5(26.3)$ & \\
\hline $\mathrm{CT}+\mathrm{HT}+/-\mathrm{BT}$ & $7(10.2)$ & $4(8.0)$ & $3(15.8)$ & \\
\hline
\end{tabular}

\#Two-sample Wilcoxon rank-sum (Mann-Whitney) test for age, fisher exact test for histological subtype, grading and type of therapy and chi square for the remaining variables.

CT, chemotherapy; HT, hormonal therapy; BT, biological therapy.

providing heterogeneous and inconsistent data on early $\mathrm{BC}$ and adjuvant setting [6].

Despite the limitations of the this study, among which are the retrospective design and the low number of samples, we demonstrated the feasibility of CF-DNA evaluation on serum samples stored for a long period of time. We analyzed only serum samples collected before surgery (baseline). Our results confirmed literature data $[7,8]$ as CF-DNA quantity was significantly higher in terms of quantity (ng) of HER2 short, BCAS1 and PI3KCA short in $\mathrm{BC}$ patients than in healthy controls.
Despite our expectations, healthy controls showed higher II and lower AI of BCAS1, MYC and PI3KCA oncogenes than $\mathrm{BC}$ patients, in accordance with Ellinger et al. [18]. The potential prognostic value of HER2 and $P I 3 K C A$ as oncogenes has already been described. In particular, Garcia-Murillas and colleagues demonstrated that PI3KCA mutations detected in circulating tumor DNA can be related to microscopic residual disease that may help identify patients likely to recur [19]. In addition, Page and colleagues demonstrated the existence of amplified HER2 in CF-DNA on HER2 positive BC patients [20]. 
Table 2: CF-DNA quantity (ng) in relation to the status (cancer/control)

\begin{tabular}{|c|c|c|c|c|}
\hline \multirow[t]{2}{*}{ Gene } & $\begin{array}{l}\text { Overall } \\
(n=89)\end{array}$ & $\begin{array}{c}\text { Cancer } \\
(n=79)\end{array}$ & $\begin{array}{l}\text { Control } \\
(n=10)\end{array}$ & $p$-value ${ }^{\#}$ \\
\hline & Median (iqr range) & Median (iqr range) & Median (iqr range) & \\
\hline HER2 LONG & $0.031(0.012-0.121)$ & $0.034(0.011-0.137)$ & $0.023(0.015-0.033)$ & 0.439 \\
\hline HER2 SHORT & $0.202(0.077-0.496)$ & $0.238(0.093-0.509)$ & $0.067(0.049-0.111)$ & 0.016 \\
\hline BCAS1 LONG & $0.241(0.093-0.820)$ & $0.266(0.131-0.941)$ & $0.039(0.031-0.460)$ & 0.021 \\
\hline BCAS1 SHORT & $1.195(0.476-2.069)$ & $1.259(0.536-2.133)$ & $0.085(0.050-0.916)$ & 0.001 \\
\hline MYC LONG & $0.421(0.190-1.192)$ & $0.421(0.146-1.205)$ & $0.426(0.299-0.533)$ & 0.658 \\
\hline MYC SHORT & $1.124(0.557-2.001)$ & $1.145(0.557-2.255)$ & $0.771(0.457-1.335)$ & 0.193 \\
\hline PI3KCA LONG & $0.089(0.036-0.347)$ & $0.108(0.036-0.373)$ & $0.056(0.044-0.092)$ & 0.398 \\
\hline PI3KCA SHORT & $1.165(0.231-3.434)$ & $1.619(0.296-4.332)$ & $0.174(0.140-0.390)$ & 0.001 \\
\hline
\end{tabular}

${ }^{\#}$ Two-sample Wilcoxon rank-sum (Mann-Whitney) test.

Our principal aim was to evaluate the prognostic role of CF-DNA in all BC subtypes. Yet we did not observe any role in predicting either relapse or progression. These findings were in accordance with Garcia-Murillas et al, who found that a mutational analysis of CF-DNA at baseline was not significantly associated with disease-free survival and risk of relapse [19].

Although this study showed no association between CF-DNA and prognosis, it is nevertheless useful for planning new prospective studies that take into consideration the time of sampling (pre-surgery, post-surgery, after and during therapy, over a long-term follow-up) and the molecular alterations by liquid biopsy, such as copy number variations, mutations and integrity of other genes.

Collection time, type of biological specimens (serum vs plasma), CF-DNA alterations and an adequate method of detection need robust assays to prove their clinical validity and utility. Our study points out that the great potential of CF-DNA detected as liquid biopsy still awaits rigorous prospective studies to enable widespread clinical application.

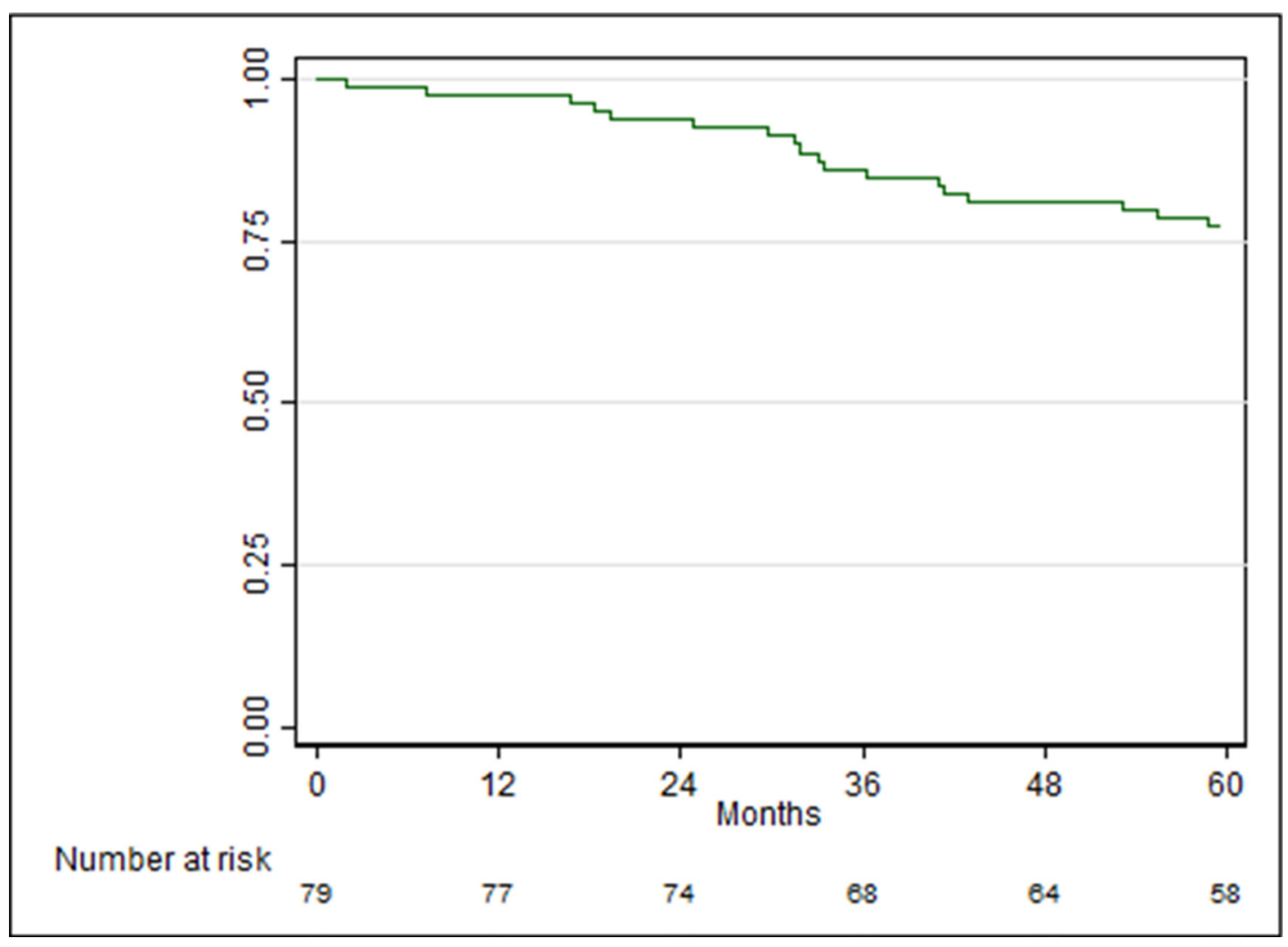

Figure 1: Recurrence-free survival (RFS) curve. 
Table 3: Integrity (II) and apoptotic (AI) indexes of each gene in relation to the status (cancer/ control)

\begin{tabular}{|l|c|c|c|c|}
\hline \multicolumn{1}{c}{ Index } & \multicolumn{1}{c}{$\begin{array}{c}\text { Overall } \\
(\boldsymbol{n}=\mathbf{8 9})\end{array}$} & $\begin{array}{c}\text { Cancer } \\
(\boldsymbol{n}=79)\end{array}$ & \multicolumn{2}{c}{$\begin{array}{c}\text { Control } \\
(\boldsymbol{n}=\mathbf{1 0})\end{array}$} \\
\cline { 2 - 6 } & \multicolumn{2}{c}{ Median (iqr range) } & Median (iqr range) & \multicolumn{2}{c}{ Median (iqr range) } \\
\hline II HER2 & $0.232(0.080-0.440)$ & $0.227(0.057-0.449)$ & $0.354(0.229-0.436)$ & 0.329 \\
\hline AI HER2 & $4.313(2.274-12.567)$ & $4.411(2.226-17.612)$ & $2.878(2.293-4.370)$ & 0.329 \\
\hline II BCAS1 & $0.296(0.179-0.445)$ & $0.286(0.163-0.401)$ & $0.520(0.386-0.687)$ & 0.002 \\
\hline AI BCAS1 & $3.379(2.248-5.611)$ & $3.501(2.493-6.143)$ & $1.925(1.455-2.591)$ & 0.002 \\
\hline II MYC & $0.428(0.229-0.660)$ & $0.406(0.210-0.636)$ & $0.657(0.428-0.914)$ & 0.030 \\
\hline AI MYC & $2.337(1.515-4.375)$ & $2.463(1.572-4.766)$ & $1.523(1.094-2.337)$ & 0.030 \\
\hline II PI3KCA & $0.102(0.055-0.286)$ & $0.092(0.051-0.190)$ & $0.365(0.240-0.806)$ & 0.004 \\
\hline AI PI3KCA & $9.759(3.499-18.268)$ & $10.852(5.272-19.679)$ & $2.759(1.240-4.165)$ & 0.004 \\
\hline
\end{tabular}

\#Two-sample Wilcoxon rank-sum (Mann-Whitney) test.

Table 4: CF-DNA quantity (ng) in relation to patient prognosis

\begin{tabular}{|c|c|c|c|c|}
\hline Gene & $\begin{array}{l}\text { Overall } \\
(n=79)\end{array}$ & $\begin{array}{c}\text { Non-relapsed } \\
(n=58)\end{array}$ & $\begin{array}{c}\text { Relapsed } \\
(n=21)\end{array}$ & $p$-value ${ }^{\#}$ \\
\hline & Median (iqr range) & Median (iqr range) & Median (iqr range) & \\
\hline HER2 LONG & $0.034(0.011-0.137)$ & $0.032(0.014-0.121)$ & $0.049(0.007-0.137)$ & 0.868 \\
\hline HER2 SHORT & $0.238(0.093-0.509)$ & $0.206(0.087-0.466)$ & $0.409(0.123-0.890)$ & 0.078 \\
\hline BCAS1 LONG & $0.266(0.131-0.941)$ & $0.238(0.093-0.798)$ & $0.292(0.169-0.970)$ & 0.339 \\
\hline BCAS1 SHORT & $1.269(0.536-2.133)$ & $1.277(0.525-2.275)$ & $1.269(0.677-2.069)$ & 0.824 \\
\hline MYC LONG & $0.421(0.146-1.205)$ & $0.364(0.164-1.379)$ & $0.485(0.120-1.048)$ & 0.965 \\
\hline MYC SHORT & $1.145(0.557-2.255)$ & $1.136(0.557-2.246)$ & $1.185(0.689-2.255)$ & 0.689 \\
\hline PI3KCA LONG & $0.108(0.036-0.373)$ & $0.082(0.032-0.315)$ & $0.195(0.049-0.472)$ & 0.226 \\
\hline PI3KCA SHORT & $1.619(0.296-4.332)$ & $1.630(0.251-3.198)$ & $1.619(0.338-4.365)$ & 0.549 \\
\hline
\end{tabular}

\#Two-sample Wilcoxon rank-sum (Mann-Whitney) test.

Table 5: Integrity (II) and apoptotic (AI) indexes of each gene in relation to patient prognosis

\begin{tabular}{|c|c|c|c|c|}
\hline \multirow{2}{*}{ Index } & $\begin{array}{l}\text { Overall } \\
(n=79)\end{array}$ & $\begin{array}{l}\text { Non-relapsed } \\
\quad(n=58)\end{array}$ & $\begin{array}{c}\text { Relapsed } \\
(n=21)\end{array}$ & \multirow{2}{*}{$p$-value ${ }^{\#}$} \\
\hline & Median (iqr range) & Median (iqr range) & Median (iqr range) & \\
\hline II HER2 & $0.227(0.057-0.449)$ & $0.227(0.085-0.440)$ & $0.188(0.022-0.556)$ & 0.351 \\
\hline AI HER2 & $4.411(2.226-17.612)$ & $4.411(2.274-11.698)$ & $5.332(1.799-46.085)$ & 0.351 \\
\hline II BCAS1 & $0.286(0.163-0.401)$ & $0.285(0.137-0.396)$ & $0.291(0.242-0.429)$ & 0.277 \\
\hline AI BCAS1 & $3.510(2.493-6.143)$ & $3.510(2.525-7.320)$ & $3.439(2.329-4.133)$ & 0.277 \\
\hline II MYC & $0.406(0.210-0.636)$ & $0.410(0.200-0.655)$ & $0.375(0.237-0.558)$ & 0.534 \\
\hline AI MYC & $2.463(1.572-4.766)$ & $2.441(1.526-5.011)$ & $2.902(1.793-4.219)$ & 0.534 \\
\hline II PI3KCA & $0.092(0.051-0.190)$ & $0.083(0.050-0.174)$ & $0.118(0.081-0.260)$ & 0.120 \\
\hline AI PI3KCA & $10.852(5.272-19.679)$ & $12.042(5.757-19.931)$ & $8.487(3.851-12.327)$ & 0.120 \\
\hline
\end{tabular}

\#Two-sample Wilcoxon rank-sum (Mann-Whitney) test. 
Table 6: Primer sequences and amplicons length

\begin{tabular}{|l|l|c|}
\hline \multicolumn{2}{c|}{ Gene } & \multicolumn{2}{c|}{ Primer sequence } & 295 \\
\hline HER2 long & $\begin{array}{l}\text { Fw-CCAGGGTGTTCCTCAGTTGT } \\
\text { Rev-TCAGTATGGCCTCACCCTTC }\end{array}$ & 126 \\
\hline MY2 short & $\begin{array}{l}\text { Fw- CCAGGGTGTTCCTCAGTTGT } \\
\text { Rev-GGAGTTCCTGCAGAGGACAG }\end{array}$ & 264 \\
\hline MYC short & $\begin{array}{l}\text { Fw TGGAGTAGGGACCGCATATC } \\
\text { Rev-ACCCAACACCACGTCCTAAC }\end{array}$ & 128 \\
\hline BCAS1 long & $\begin{array}{l}\text { Fw-GGCATTTAAATTTCGGCTCA } \\
\text { Rev-AAAAGCCAAATGCCAACTT }\end{array}$ & 266 \\
\hline BCAS1 short & $\begin{array}{l}\text { Fw-GGGTCAGAGCTTCCTGTGAG } \\
\text { Rev CGTTGTCCTGAAACAGAGCA }\end{array}$ & 229 \\
\hline PI3KCA long & $\begin{array}{l}\text { Fw-GGGTCAGAGCTTCCTGTGAG } \\
\text { Rev-TATCATGCCTTGGAGAACCA }\end{array}$ \\
\hline PI3KCA short & $\begin{array}{l}\text { Fw-CTC CACGAC CAT CATCAGGT } \\
\text { Rev- CGAAGGTCACAAAGTCGTCT }\end{array}$ \\
\hline
\end{tabular}

\section{MATERIALS AND METHODS}

\section{Case series}

A total of 79 serum samples were collected before surgery from women at first diagnosis of $\mathrm{BC}$ at the Breast Unit of the Morgagni-Pierantoni Hospital (Forlì, Italy) from 2002 to 2010 . Twenty-one relapsed and 58 nonrelapsed patients (approximately 1:3 ratio) were matched by subtype and age. Blood samples were also collected from 10 healthy donors. Recurrent disease in patients was defined as local, regional and distant relapse occurring at over 6 months of surgery.

The study protocol was reviewed and approved by IRST and AVR (Area Vasta Romagna, Wide Romagna Catchment Area) Ethics Committee (approval number 1267) and written informed consent was provided by each patient.

The healthy control group, reporting neither previous disease nor cancer, was matched to the patients by gender and age. CF-DNA quantity and integrity analysis was performed blindly on all individuals and was evaluable for the entire case series.

From each patient, $5 \mathrm{ml}$ whole blood was collected in tubes without anticoagulant prior to surgery and centrifuged at $2500 \mathrm{~g}$ for $15 \mathrm{~min}$ within $2 \mathrm{~h}$ of collection. The supernatants were transferred into cryovials and immediately stored at $-80^{\circ} \mathrm{C}$ until use.

\section{CF-DNA analysis}

DNA was extracted and purified from $500 \mu \mathrm{l}$ serum by Qiamp DNA minikit (Qiagen, Milan, Italy) according to the manufacturer's instructions. At the same time, DNA was extracted from a human genomic control using the same kit. DNA was quantified by spectrophotometry (NanoDrop ND-1000; Celbio, Milan, Italy). Real Time PCR reactions were carried out by Rotor Gene 6000 detection system (Corbett Research, St. Neots, UK) using IQ SYBR Green (Bio-Rad, Milan, Italy). All samples were analyzed for CF-DNA quantity and integrity of HER2, MYC, BCAS1 and PI3KCA oncogenes.

Sequences $>260$ bp ("long"), corresponding to 4 oncogenes, were analyzed in addition to shorter sequences ( $\leq 125 \mathrm{bp}$, "short") of the same genes, corresponding to: HER2 (locus 17q12), MYC (locus 8q24 and 21), BCAS1 (locus 20q.13.2), PI3KCA (locus 3q26.3). Primer sequences and amplicons length are shown in Table 6.

PCR conditions for the long fragments were as follows: $95^{\circ} \mathrm{C}$ for $3 \mathrm{~min} ; 45$ cycles at $94^{\circ} \mathrm{C}$ for $40 \mathrm{sec}$; $56^{\circ} \mathrm{C}$ for $40 \mathrm{sec} ; 72^{\circ} \mathrm{C}$ for $1 \mathrm{~min}$.

PCR conditions for the short fragments were as follows: $95^{\circ} \mathrm{C}$ for $90 \mathrm{sec} ; 40$ cycles at $95^{\circ} \mathrm{C}$ for $15 \mathrm{sec}$; $54^{\circ} \mathrm{C}$ for $45 \mathrm{sec}$.

All Real Time PCR reactions were performed in duplicate on $10 \mathrm{ng}$ of each DNA sample. Various amounts of DNA from the human genomic control $(0.01,0.1,1$, 5,10 and $20 \mathrm{ng}$ ) were also analyzed to draw a standard curve. CF-DNA value for each sample was obtained by Rotor Gene 6000 detection system software using standard curve interpolation. Analysis was repeated whenever the difference between duplicate samples was $>1$ cycle threshold. Real Time experiments were performed independently in duplicate on the same 8 samples to test assay imprecision. The coefficients of variation were then calculated for HER2, MYC, BCAS1 and PI3KCA long and short fragments.

The CF-DNA II was calculated as the ratio of quantity of long fragment/short fragment. The CF-DNA AI was $1 /$ II. 


\section{Statistical analysis}

Frequency tables were performed for categorical variables. Continuous variables were presented using median and range or iqr range. The relationship between clinic-pathological factors and prognosis was analyzed using a non-parametric ranking statistic test. Normality of data distribution was tested using Shapiro-Wilk test: data distribution was not normal and non-parametric statistical tests were used (Wilcoxon Mann-Whitney and chi-square test) to evaluate difference between relapsed/non-relapsed patients and between $\mathrm{BC}$ patients and healthy controls.

To evaluate the most discriminant cut-off values between relapsed and non-relapsed patients we used the receiver operating characteristic (ROC) curve analysis. True positive rates (sensitivity) were plotted against false positive rates (1-specificity) for all classification points.

Conditional logistic regression model was carried out to fully account for the structure of the data matched by histological subtype and age. OR and their $95 \% \mathrm{CI}$ for patient prognosis were reported to identify factors independently associated with relapse of disease.

RFS was calculated from time of surgical treatment to time of disease relapse or death. $p<0.05$ was considered statistically significant. Statistical analyses were carried out with STATA (version 14.1 for Windows, Stata-Corp, College Station, TX, USA).

\section{ACKNOWLEDGMENTS}

The authors would like to thank Veronica Zanoni for linguistic support.

\section{CONFLICTS OF INTEREST}

None.

\section{GRANT SUPPORT}

None.

\section{ETHICAL APPROVAL}

The study was approved by the Medical Scientific Committee of IRST IRCCS, the Ethics Committee of Area Vasta Romagna, Italy (approval no. 1267).

\section{REFERENCES}

1. Early Breast Cancer Trialists' Group (EBCTCG). Effects of chemotherapy and hormonotherapy for early breast cancer on recurrence and 15-year survival: an overview of randomized trials. Lancet. 2005; 365:1687-1717.

2. Khatcheressian JL, Hurley P, Bantug E, Esserman LJ, Grunfeld E, Halberg F, Hantel A, Henry NL, Muss HB,
Smith TJ, Vogel VG, Wolff AC, Somerfield MR, et al. Breast cancer follow-up and management after primary treatment. American society of clinical oncology clinical practice guideline update. J Clin Oncol. 2013; 31:961-965.

3. Leon SA, Shapiro B, Sklaroff DM, Yaros MJ. Free DNA in the serum of cancer patients and the effect of therapy. Cancer Res. 1977; 37:646-50.

4. Panabieres CA, Schwarzenbach H, Pantel K. Circulating tumor cells and circulating Tumor DNA. Annu Rev Med. 2012; 63:199-215.

5. Matikas A, Syrigos KN, Agelaki S. Circulating Biomarkers in Non-Small-Cell Lung Cancer: Current Status and Future Challenges. Clin Lung Cancer. 2016; S1525-7304:30137-1.

6. De Mattos-Arruda L, Caldas C. Cell-free circulating tumour DNA as a liquid biopsy in breast cancer. Mol Oncol. 2016; 10:464-74.

7. Szpechcinski A, Chorostowska-Wynimko J, Kupis W, Maszkowska-Kopij K, Dancewicz M, Kowalewski J, Orlowski T. Quantitative analysis of free-circulating DNA in plasma of patients with resectable NSCLC. Expert Opin Biol Ther. 2012; 12:S3-9.

8. Paci M, Maramotti S, Bellesia E, Formisano D, Albertazzi L, Ricchetti T, Ferrari G, Annessi V, Lasagni D, Carbonelli C, De Franco S, Brini M, Sgarbi G, et al. Circulating plasma DNA as diagnostic biomarker in nonsmall cell lung cancer. Lung Cancer. 2009; 64:92-97.

9. Schwarzenbach H, Pantel K. Circulating DNA as biomarker in breast cancer. Breast Cancer Res. 2015; 17:136.

10. Le Du F, Ueno NT, Gonzalez-Angulo AM. Breast Cancer Biomarkers: Utility in Clinical Practice. Curr Breast Cancer Rep. 2013; 5. doi: 10.1007/s12609-013-0125-9.

11. Li BT, Drilon A, Johnson ML, Hsu M, Sima CS, McGinn C, Sugita H, Kris MG, Azzoli CG. A prospective study of total plasma cell-free DNA as a predictive biomarker for response to systemictherapy in patients with advanced nonsmall-cell lung cancers. Ann Oncol. 2016; 27:154-9.

12. Casadio V, Calistri D, Salvi S, Gunelli R, Carretta E, Amadori D, Silvestrini R, Zoli W. Urine Cell-Free DNA Integrity as a Marker for Early Prostate Cancer Diagnosis: A Pilot Study. Biomed Res Int. 2013; 2013:270457.

13. Salvi S, Casadio V, Conteduca V, Burgio SL, Menna C, Bianchi E, Rossi L, Carretta E, Masini C, Amadori D, Calistri D, Attard G, De Giorgi U. Circulating cell-free $A R$ and $C Y P 17 A 1$ copy number variations may associate with outcome of metastatic castration-r esistant prostate cancer patients treated with abiraterone. Br J Cancer. 2015; 112: $1717-1724$.

14. Board RE, Wardley AM, Dixon JM, Armstrong AC, Howell S, Renshaw L, Donald E, Greystoke A, Ranson M, Hughes A, Dive C. Detection of PIK3CA mutations in circulating free DNA in patients with breast cancer. Breast Cancer Res Treat. 2010; 120:461-467.

15. Bechmann T, Andersen RF, Pallisgaard N, Madsen JS, Maae E, Jakobsen EH, Bak Jylling AM, Steffensen KD, 
Jakobsen A. Plasma HER2 amplification in cell-free DNA during neoadjuvant chemotherapy in breast cancer. J Cancer Res Clin Oncol. 2013; 139:995-1003.

16. Roth C, Pantel K, Müller V, Rack B, Kasimir-Bauer S, Janni W, Schwarzenbach H. Apoptosis-related deregulation of proteolytic activities and high serum levels of circulating nucleosomes and DNA in blood correlate with breast cancer progression. BMC Cancer. 2011; 11:4.

17. Hashad D, Sorour A, Ghazal A, Talaat I. Free circulating tumor DNA as a diagnostic marker for breast cancer. J Clin Lab Anal. 2012; 26:467-472.

18. Ellinger J, Bastian PJ, Ellinger N, Kahl P, Perabo FG, Büttner R, Müller SC, Ruecker AV. Apoptotic DNA fragments in serum of patients with muscle invasive bladder cancer: a prognostic entity. Cancer Lett. 2008; 264:274-80.

19. Garcia-Murillas I, Schiavon G, Weigelt B, Ng C, Hrebien S, Cutts RJ, Cheang M, Osin P, Nerurkar A, Kozarewa I, Garrido JA, Dowsett M, Reis-Filho JS. Mutation tracking in circulating tumor DNA predicts relapse in early breast cancer. Sci Transl Med. 2015; 7:302:302ra133.

20. Page K, Hava N, Ward B, Brown J, Guttery DS, Ruangpratheep C, Blighe K, Sharma A, Walker RA, Coombes RC, Shaw JA. Detection of HER2 amplification in circulating free DNA in patients with breast cancer. Br J Cancer. 2011; 104:1342-8. 